\title{
Decision-making impairment in obsessive-compulsive disorder as measured by the lowa Gambling Task
}

\author{
Felipe Filardi da Rocha', Nathália Bueno Alvarenga², \\ Leandro Malloy-Diniz ${ }^{3,4}$, Humberto Corrêa1,5
}

\begin{abstract}
Objective: This study aims to evaluate the process of decision-making in patients with obsessive-compulsive disorder (OCD) using the lowa Gambling Task (IGT). In addition, we intend to expand the understanding of clinical and demographic characteristics that influence decision-making. Method: Our sample consisted of 214 subjects (107 diagnosed with $O C D$ and 107 healthy controls) who were evaluated on their clinical, demographic and neuropsychological features. Moreover, the lowa Gambling Task (IGT), a task that detects and measures decision-making impairments, was used. Results: We found that OCD patients performed significantly worse on the IGT. Furthermore, features such as symptoms of anxiety did not influence IGT performance. Conclusion: Impaired decision-making seems to be a key feature of OCD. Given that OCD is a complex heterogeneous disorder, homogeneous groups are necessary for an accurate characterization of our findings. Key words: behavior, obsessive-compulsive disorder, cognition, serotonin.
\end{abstract}

\section{Prejuízo no processo de tomada de decisão mensurado pelo lowa Gambling Task no transtorno obsessivo-compulsivo}

\section{RESUMO}

Objetivo: Avaliar o processo de tomada de decisão em pacientes com transtorno obsessivo-compulsivo (TOC) utilizando o lowa Gambling Task. Pretende-se, também, avaliar características demográficas e clínicas que possam influenciar essa função executiva. Método: Nossa amostra é composta de 214 sujeitos (107 pacientes com diagnóstico de TOC e 107 controles) que foram avaliados do ponto de vista clínico, demográfico e neuropsicológico. O lowa Gambling Task, um teste que avalia o processo de tomada de decisão, foi aplicado. Resultados: Observamos um prejuízo no desempenho dos pacientes com TOC no IGT. Características como sintomas depressivos e ansiosos não foram responsáveis por esse prejuízo. Conclusão: $\bigcirc$ prejuízo no processo de tomada de decisão parece ser um componente importante na fisiopatologia do TOC. Como o TOC é um transtorno heterogêneo, grupos mais homogêneos são necessários para uma melhor caracterização e confirmação dos nossos achados.

Palavras-chave: comportamento, transtorno obsessivo-compulsivo, cognição, serotonina.

Correspondence

Felipe Filardi da Rocha

Rua Sapucaia 83

35460-000 Brumadinho MG - Brasil

E-mail: fil_bh@yahoo.com.br

Received 29 December 2010

Received in final form 19 March 2011

Accepted 28 March 2011
Obsessive-compulsive disorder (OCD) is a debilitating neuropsychiatric disorder $^{1}$. Many neuropsychological studies have suggested that OCD patients have impairments in executive functions, including flexible response, attention, working memory, non-verbal memory and inhibitory control ${ }^{2-17}$.

Considering the heterogeneity of clinical manifestations of executive functions, some authors emphasize the division between "cold" and "hot" components of ex-

Universidade Federal de Minas Gerais (UFMG), Belo Horizonte MG, Brazil: 'Molecular Program; ${ }^{2}$ Medical Graduate Student; ${ }^{3}$ Department of Psychology; ${ }^{4}$ Neuroscience Program; ${ }^{5}$ Department of Mental Health, Faculty of Medicine. 
ecutive functions ${ }^{4}$. The former component of executive function is related to the dorsolateral prefrontal network and encompasses mechanistic cognitive abilities (e.g., planning, problem-solving, working memory abstract reasoning). The latter component is related to the orbitofrontal prefrontal network and involves functions such as interpersonal and social behavior, real life decision-making and emotional regulation during social interaction ${ }^{1-9}$.

Interestingly, neuroimaging studies in patients with OCD have demonstrated functional abnormalities in these brain regions, mainly in the orbitofrontal cortex (OFC), partially explaining the neuropsychological impairments that are associated with $\mathrm{OCD}^{2,3,10,11}$.

Decision-making is a cognitive skill that integrates environmental information to make beneficial decisions $^{18,19}$. Given that obsessive-compulsive symptoms may involve deficiencies in the decision-making process, it is important to understand the role of decisionmaking in $\mathrm{OCD}^{4-6,12}$.

The Iowa Gambling Task (IGT) is a well-known neuropsychological method used to study decision-making. It is a card game that detects and measures decisionmaking impairments ${ }^{20}$. Only five independent studies have used the IGT to study OCD patients. Nielen et al. ${ }^{12}$ did not find differences between patients and healthy volunteers. Furthermore, the same study demonstrated that IGT performance was associated with the severity of OCD and anxiety symptoms. Starcke et al. ${ }^{4,5}$ observed that impaired IGT performance was accompanied by reduced skin conductance responses during task performance. Another study demonstrated similar results in patients with prominent hoarding symptoms ${ }^{13}$. Finally, three more studies demonstrated poor performance of OCD patients on IGT, although these studies had a small number of patients ${ }^{14,21}$.

Thus, given that only a few studies have been conducted, we set out to explore the relevance of the decision-making process in the psychopathology of OCD. We specifically aimed to evaluate the influence of clinical, demographic and "cold" neuropsychological features on IGT performance in a sample of OCD patients.

\section{METHOD}

\section{Participants and clinical assessments}

The study sample consisted of 107 Brazilian-Caucasian OCD patients (between the ages of 18 and 48 years) admitted consecutively as inpatients or outpatients in a psychiatric unit that is specialized in the treatment of patients with OCD. A trained psychiatrist made the diagnosis using a structured MINI-PLUS interview ${ }^{22}$ following DSM-IV criteria, as well as a complete review of medical records and an interview with (at a minimum) a close relative.
In order to be included, the subjects had to be of Brazilian-Caucasian descent, as determined by self and/or clinical evaluation. Any participants with a current diagnosis of moderate/severe major depressive disorder, manic/hypomanic episode, substance-related disorders, psychotic disorders, or a lifetime history of traumatic brain injury/vascular brain disorder were excluded from the study.

All patients were evaluated using the Yale-Brown Obsessive-Compulsive Scale (Y-BOCS $)^{23,24}$, the Beck Depression Inventory (BDI) ${ }^{25}$, the Beck Anxiety Inventory $(\mathrm{BAI})^{26}$ and the Dimensional Yale-Brown ObsessiveCompulsive Scale ${ }^{27}$.

The patients were prescribed the following medications: fifty-two patients (51.48\%) were prescribed selective serotonin reuptake inhibitors, fifteen (14.85\%) were prescribed clomipramine, six (5.94\%) were given clomipramine plus risperidone, six (5.94\%) were prescribed selective serotonin reuptake inhibitors plus risperidone, and twenty-two (21.98\%) were unmedicated. All medicated patients received the same dose of psychotropic medications for at least 16 weeks, thereby minimizing the effect of their medication on the treatment of OCD or its comorbidities.

The following comorbidities (axis I diagnosis) were observed in our patients: social phobia $(\mathrm{n}=22 ; 21.78 \%)$, generalized anxiety disorder $(\mathrm{n}=22 ; 21.78 \%)$, agoraphobia $(\mathrm{n}=19 ; 18.81 \%)$, depressive disorder $(\mathrm{n}=16 ; 15.84 \%)$, panic disorder $(\mathrm{n}=15 ; 14.85 \%)$, smoking $(\mathrm{n}=6 ; 5.94 \%)$ and bipolar disorder $(n=2 ; 1.98 \%$ - both presented with bipolar subtype II and were interviewed in euthimia).

Finally, 107 healthy controls who were free of psychiatric illness and had no familial history of axis I psychiatric disorder in their first-degree relatives were also screened using the MINI-PLUS. Participants were recruited through local advertisements and were submitted to the same neuropsychological tasks as OCD patients, including the BAI and BDI scales. Furthermore, patients and controls were matched by age, years of formal education and intellectual level, as measured by Progressive Matrices of Raven ${ }^{28}$.

\section{Neuropsychological instruments}

A trained neuropsychologist administered the cognitive tests in a laboratory setting. The measures were administered in a fixed order: Raven Progressive Matrices, IGT $^{20}$ and Continuous Performance Task (CPT-II) (described below). The examiner was blind to the diagnosis of the subject being tested.

[1] We evaluated the potential contribution of intelligence using the Raven Progressive Matrices.

[2] We used a computerized version of the IGT. Briefly, subjects had to choose one card at a time from 
four possible decks (A, B, C, and D). The task required the subjects to make 100 choices (100 trials), winning or losing a certain amount of money in each trial. During the instructions for the game, subjects were told that some of the decks were more advantageous than others; however, they did not know which decks were better. After each choice, the subjects received feedback on the computer screen, telling them how much money they had won or lost. Through this feedback, subjects learn to avoid decks that yielded high immediate gains but led to larger future losses (decks A and B) and favor the decks that led to a small immediate gain but avoided substantial losses over the course of the task (decks $\mathrm{C}$ and D). The 100 choices were divided into five blocks of 20 choices each, allowing us to verify changes in the pattern of choices throughout the task. For each block, we used the following formula: (number of Deck C choices + number of Deck D choices) - (number of Deck A choices + number of Deck B choices). The total IGT score was then obtained by subtracting the total number of disadvantageous decks from that of the advantageous decks $[(C+D)-(A+B)]$ for 100 cards. We then obtained two IGT subscores by subtracting the total number of disadvantageous decks from that of the advantageous decks $[(\mathrm{C}+\mathrm{D})-(\mathrm{A}+\mathrm{B})]$ for trials $1-50$ and trials $51-100$.

[3] The CPT-II provides measures of sustained attention and motor impulsiveness. On this task, the subject is instructed to press a spacebar when any letter other than the letter X appears on screen. An omission error occurs when the subject fails to press the spacebar when a letter other than $\mathrm{X}$ appears; omission errors reflect a failure to react to a target stimulus. A commission error occurs when the subject presses the spacebar when the letter $\mathrm{X}$ appears on the screen; commission errors reflect a failure to inhibit a pre-potent motor response. We used omission and commission errors as dependent measures to evaluate attentional and motor impulsivity, respectively

\section{Statistical analysis}

Statistical analysis for categorical data was performed using the qui-square test, and differences between groups were assessed using a Student one-tailed t-test. Correlations were measured using Pearson's coefficients within the OCD and control groups, indicating the strength and direction of the linear relationships between random variables. The results were considered significant when $\mathrm{p} \leq 0.05$.

\section{Ethics}

All procedures were approved by the local ethics committee and were completed in accordance with the Helsinki Declaration of 1975. All participants signed an informed consent form after the study had been fully explained to them.

\section{RESULTS}

\section{OCD vs. Controls}

A clinical and socio-demographic characterization of the sample is provided in Table 1. No significant differences were observed between the control and patient groups in terms of age, gender, years of formal education, or intelligence. We observed worse performance on IGT in OCD patients, as well as more anxiety and depressive symptoms (Table 1).

\section{IGT performance: the influence of}

\section{social-demographic and clinical features}

Analysis of Pearson's coefficients demonstrated positive correlations between the IGT net score and first and second half of IGT and between the first half of the task and the second.

A positive correlation was observed between BAI scores and BDI and YBOCS scores in OCD. Age of onset was also positively correlated with BAI and BDI scores.

Healthy volunteers and OCD patients did not demonstrate any correlations between social demographic, clinical features (anxiety and depressive symptoms), CPT-II results and IGT performance (Tables 2 and 3). Furthermore, the performance was not correlated with gender, age, years of formal education and intellectual level (data not shown).

\section{CPT-II performance: the influence of} social-demographic and clinical features

OCD patients demonstrated that clinical features influence the task's performance. While a negative correlation between anxiety symptoms and commission errors was observed, omission errors positively associated to depressive symptoms and the intensity of obsessivecompulsive symptoms.

\section{DISCUSSION}

We observed that OCD patients performed significantly worse on the IGT. We also assessed several clinical features such as anxiety symptoms and the performance on CPT-II, demonstrating that they did not influence IGT performance in the OCD or control groups.

However, we did observe correlations between the severity of obsessive and compulsive symptoms and clinical features such as depression symptoms and age of onset. One simple explanation is that longer periods of disease and more severe symptoms lead to more anxiety and depression symptoms. Furthermore, anxiety, depression and OCD have common neurochemical dysfunction in the serotonergic system ${ }^{1,29,30}$. 
Table 1. Comparison between clinical, social-demographic and neuropsychological variables of patients with OCD and controls.

\begin{tabular}{|c|c|c|c|}
\hline & $\mathrm{OCD}(n=107)$ & Controls $(n=107)$ & $p$ \\
\hline \multicolumn{4}{|l|}{ Demographic characteristics } \\
\hline Age, mean $\pm S D$ years & $28.40 \pm 14.12$ & $29.33 \pm 13.22$ & $p>0.05$ \\
\hline Gender, male (\%) & $54.20 \%(n=58)$ & $52.33 \%(n=56)$ & $p>0.05$ \\
\hline Marital status, married (\%) & $31.75 \%(n=34)$ & $36.44 \%(n=39)$ & $p>0.05$ \\
\hline Years of formal education $\pm S D$, years & $10.87 \pm 4.75$ & $10.26 \pm 5.02$ & $p>0.05$ \\
\hline \multicolumn{4}{|l|}{ Clinical features } \\
\hline Intelligence & $42.08 \pm 6.70$ & $41.95 \pm 7.56$ & $p>0.05$ \\
\hline Duration of illness, mean $\pm S D$, months & $111.54 \pm 94.36$ & - & - \\
\hline Age at onset, mean $\pm S D$, years & $18.54 \pm 9.94$ & - & - \\
\hline Duration of untreated illness, mean $\pm S D$, months & $78.40 \pm 43.01$ & - & - \\
\hline Y-BOCS score, mean \pm SD & - & - & - \\
\hline Obsessions & $12.20 \pm 1.96$ & - & - \\
\hline Compulsions & $14.33 \pm 5.31$ & - & - \\
\hline Total & $26.61 \pm 7.70$ & - & - \\
\hline $\mathrm{BAl}$, mean $\pm \mathrm{SD}$ & $20.14 \pm 9.98$ & $7.42 \pm 4.66$ & $\mathrm{p}<0.01$ \\
\hline $\mathrm{BDI}$, mean $\pm \mathrm{SD}$ & $9.97 \pm 5.86$ & $4.21 \pm 3.06$ & $\mathrm{p}<0.01$ \\
\hline Absence of axis I comorbidity (\%) & $23.36 \%(n=25)$ & - & - \\
\hline Familial history of OCD (at least one first-degree relative with OCD) & $14.01 \%(n=15)$ & - & - \\
\hline OCD symptoms dimensions & - & - & - \\
\hline Obsessions/checking & $38.31 \%(n=41)$ & - & - \\
\hline Symmetry/ordering & $54.20 \%(n=58)$ & - & - \\
\hline Contamination/cleaning & $59.81 \%(n=64)$ & - & - \\
\hline Hoarding & $5.60 \%(n=6)$ & - & - \\
\hline \multicolumn{4}{|l|}{ lowa Gambling Test } \\
\hline IGT - Net Score & $-4.96 \pm 12.85$ & $6.42 \pm 21.88$ & $\mathrm{p}<0.01$ \\
\hline IGT $-[(C+D)-(A=B)]$ for first fifth cards & $-0.94 \pm 15.43$ & $0.76 \pm 18.43$ & $\mathrm{p}>0.05$ \\
\hline IGT $-[(C+D)-(A=B)]$ for second fifth cards & $-2.78 \pm 11.08$ & $6.87 \pm 15.33$ & $\mathrm{p}<0.01$ \\
\hline \multicolumn{4}{|l|}{ CPT-II } \\
\hline Omission errors, mean $\pm \mathrm{SD}$ & $15.30 \pm 33.65$ & $3.04 \pm 3.41$ & $\mathrm{p}<0.01$ \\
\hline Comission errors, mean $\pm S D$ & $14.76 \pm 8.02$ & $9.54 \pm 7.34$ & $\mathrm{p}<0.01$ \\
\hline
\end{tabular}

OCD:Obsessive-Compulsive Disorder; SD: Standart Deviation; Y-BOCS: Yale-Brown Obsessive Compulsive Scale; BAI: Beck Anxiety Inventory; BDI: Beck Depression Inventory; IGT: lowa Gambling Test; CPT-II: Continuos Performance Task.

Evidence of impairments in the decision-making process associated with OCD indirectly corroborates the hypothesis of fronto-subcortical circuit dysfunction. Functional neuroimaging techniques have demonstrated hyperfrontality in OCD patients, suggesting the central involvement of cortico-striato-thalamic circuits $^{2-4}$. The results of structural MRIs of selected regions of interest have consistently shown reduced grey matter volume in the OFC in patients with OCD, and the integrity of this circuit is believed to be specifically related to the decision-making process ${ }^{1,10,18,19}$. According to Starke et al. ${ }^{4}$, deficits in decision-making tasks that are related to dysfunctions of the orbitofrontal cortex are more significant that those in tasks related to the dorsolateral prefrontal cortex in patients with OCD. Moreover, the decisionmaking impairments seen in OCD patients are significantly worse than those found in other psychiatric disorders, such as schizophrenia or panic disorder, where the dorsolateral prefrontal cortex is mainly compromised ${ }^{14,21}$.

Our results corroborate these findings, since clinical characteristics influence the performance on CPTII, which is a task that is related to the dorsolateral prefrontal cortex. Therefore, poor performance on the IGT seems to be a major symptom of OCD.

Recently, Viswanath et al. ${ }^{31}$ measured the neuropsychological performance of unaffected siblings of individuals with familial OCD. They compared these unaffected siblings to matched healthy controls and found 
Table 2. Correlations ( $r$ ) between clinical and neuropsychological ("cold") features and IGT performance of OCD patients.

\begin{tabular}{|c|c|c|c|c|c|c|c|c|c|}
\hline & 1 & 2 & 3 & 4 & 5 & 6 & 7 & 8 & 9 \\
\hline 1 Commission error & $x$ & .29 & -.07 & -.11 & -.09 & .01 & $-.25^{*}$ & -.16 & .05 \\
\hline 2 Omission error & & $x$ & -.12 & -.02 & -.16 & .14 & .08 & $.21^{*}$ & $.43^{* *}$ \\
\hline 3 IGT - Net score & & & $x$ & $.57^{* *}$ & $.41^{* *}$ & .11 & .08 & .04 & .02 \\
\hline 4 IGT - First half & & & & $x$ & $.52^{* *}$ & -.06 & .03 & -.08 & .04 \\
\hline 5 IGT - Second half & & & & & $x$ & .17 & .17 & -.15 & .10 \\
\hline 6 Age of onset & & & & & & $x$ & $.28^{* *}$ & $.22^{*}$ & .12 \\
\hline $7 \mathrm{BAl}$ & & & & & & & $x$ & $.34^{* *}$ & $.23^{*}$ \\
\hline $8 \mathrm{BDI}$ & & & & & & & & $x$ & .17 \\
\hline 9 YBOCS & & & & & & & & & $x$ \\
\hline
\end{tabular}

${ }^{*} \mathrm{p}<0.05 ;{ }^{* *} \mathrm{p}<0.01$; OCD:Obsessive-Compulsive Disorder; IGT: lowa Gambling Test; BAI: Beck Anxiety Inventory; BDI: Beck Depression Inventory; Y-BOCS: Yale-Brown Obsessive Compulsive Scale.

Table 3. Correlations ( $r$ ) between clinical and neuropsychological ("cold") features and IGT performance of controls.

\begin{tabular}{|c|c|c|c|c|c|c|c|c|c|}
\hline & 1 & 2 & 3 & 4 & 5 & 6 & 7 & 8 & 9 \\
\hline 1 Commission error & $x$ & .06 & -.17 & .08 & -.11 & $x$ & .21 & .19 & $x$ \\
\hline 2 Omission error & & $x$ & -.12 & -.02 & -.16 & .14 & .08 & .14 & $x$ \\
\hline 3 IGT - Net score & & & $x$ & $.57^{* *}$ & $.49^{* *}$ & .11 & .08 & .04 & $x$ \\
\hline 4 IGT - First half & & & & $x$ & $.61^{* *}$ & -.06 & .03 & -.08 & $x$ \\
\hline 5 IGT - Second half & & & & & $x$ & .17 & .17 & -.15 & $x$ \\
\hline 6 Age of onset & & & & & & $x$ & $x$ & $x$ & $x$ \\
\hline $7 \mathrm{BAl}$ & & & & & & & $x$ & $.34^{* *}$ & $x$ \\
\hline $8 \mathrm{BDI}$ & & & & & & & & $x$ & $x$ \\
\hline 9 YBOCS & & & & & & & & & $x$ \\
\hline
\end{tabular}

${ }^{*} p<0.05 ;{ }^{* *} p<0.01$; IGT: lowa Gambling Test; BAI: Beck Anxiety Inventory; BDI: Beck Depression Inventory; Y-BOCS: Yale-Brown Obsessive Compulsive Scale.

significant deficits in their decision-making on the IGT, but also found that they performed equally well on several other tests that evaluate attention, different executive functions, memory and intelligence. The specific impairment in decision-making is consistent with the proposed neurobiological model for OCD involving the OFC cortex. Furthermore, they suggest that deficits in decision-making could be a potential endophenotype in OCD.

The opposite results have been observed by Nielen et al. ${ }^{12}$. This was possibly due to the small number of OCD patients evaluated in the study (27 OCD patients vs. 26 healthy subjects) as well as the poor representation of the heterogeneity of OCD. Furthermore, Lawrence et al. ${ }^{13}$ demonstrated that both OCD patients and controls showed comparable performance on the IGT. However, patients with prominent hoarding symptoms showed impaired decision-making on the IGT, indicating that several features may influence IGT performance. Furthermore, another feature that could influence performance on this task is the patients' genetic makeup, including polymorphisms of candidate genes related to neurochemistry systems. Our group recently demonstrated that enhanced IGT performance is related to polymorphisms in the La-allele of the serotonin transporter promoter ${ }^{1}$.

Intriguingly, two independent studies have shown that IGT performance predicts the outcome of anti-obsessive treatment with serotonin reuptake inhibitors in patients with OCD; patients with better IGT performance showed more favorable anti-obsessive treatment outcomes ${ }^{21,30}$. These findings may be partially related to decreased serotonergic function that is associated with decision-making and $\mathrm{OCD}^{1,18,21,30}$.

The present study has some limitations that should be highlighted. Our sample of 107 OCD patients could be considered small given the heterogeneity of OCD symptoms. However, to the best of our knowledge, this study is the largest sample that has been used to assess IGT performance in OCD patients, and is the only study that has evaluated clinical and demographic features. Nevertheless, some other potentially confounding variables, such as medication, were not controlled in this study. However, given that all medicated patients received the 
same dose of psychotropic medications for at least 16 weeks, we do not believe that this should influence our results. Furthermore, our sample size limits our ability to make proper comparisons between OCD subgroups, such as different comorbid disorders or dimensions of obsessive-compulsive symptoms, as shown by Lawrence et al. ${ }^{13}$. Although our sample was comprised of self-assigned Caucasian-Brazilian individuals, race (as determined by self and/or clinical evaluation) is a poor predictor of ancestry in Brazil, and thus an ethnic stratification bias cannot be ruled out. ${ }^{32}$

Moreover, the decision-making process is a complex cognitive process that likely involves the coordination of multiple brain structures in addition to the OFC. Thus, new neuropsychological tasks that evaluate decisionmaking in a more advanced model are needed.

In conclusion, impaired decision-making seems to be a key feature of OCD, and understanding this link is paramount to understanding OCD physiopathology and may offer insights about OCD treatment. Given that OCD is a complex heterogeneous disorder that is mediated by a range of different factors, including age of onset, gender and symptom dimensions, homogeneous groups are necessary for an accurate characterization of our findings.

\section{REFERENCES}

1. da Rocha FF, Malloy-Diniz L, Lage NV, Romano-Silva MA, de Marco LA, Correa $\mathrm{H}$. Decision-making impairment is related to serotonin transporter promoter polymorphism in a sample of patients with obsessive-compulsive disorder. Behav Brain Res 2008;195:159-163.

2. Menzies L, Chamberlain SR, Laird AR, Thelen SM, Sahakian BJ, Bullmore ET. Integrating evidence from neuroimaging and neuropsychological studies of obsessive-compulsive disorder: the orbitofronto-striatal model revisited. Neurosci Biobehav Rev 2008;32:525-549.

3. Chamberlain SR, Menzies L, Hampshire A, et al. Orbitofrontal dysfunction in patients with obsessive-compulsive disorder and their unaffected relatives. Science 2008;321:421-422.

4. Starcke K, Tuschen-Caffier B, Markowitsch HJ, Brand M. Dissociation of decisions in ambiguous and risky situations in obsessive-compulsive disorder. Psychiatry Res 2010;175:114-120.

5. Starcke K, Tuschen-Caffier B, Markowitsch HJ, Brand M. Skin conductance responses during decisions in ambiguous and risky situations in obsessivecompulsive disorder. Cogn Neuropsychiatry 2009;14:199-216.

6. Cavedini P, Gorini A, Bellodi L. Understanding obsessive-compulsive disorder: focus on decision making. Neuropsychol Rev 2006;16:3-15.

7. Yücel M, Harrison BJ, Wood SJ, et al. Functional and biochemical alterations of the medial frontal cortex in obsessive-compulsive disorder. Arch Gen Psychiatry 2007;64:946-955.

8. Rao NP, Reddy YC, Kumar KJ, Kandavel T, Chandrashekar CR. Are neuropsychological deficits trait markers in OCD? Prog Neuropsychopharmacol Biol Psychiatry 2008;32:1574-1579.

9. Chamberlain SR, Blackwell AD, Fineberg NA, Robbins TW, Sahakian BJ. The neuropsychology of obsessive compulsive disorder: the importance of failures in cognitive and behavioural inhibition as candidate endophenotypic markers. Neurosci Biobehav Ver 2005;29:399-419.

10. Harrison BJ, Soriano-Mas C, Pujol J, et al. Altered corticostriatal functional connectivity in obsessive-compulsive disorder. Arch Gen Psychiatry 2009; 66:1189-1200.
11. Schlösser RG, Wagner G, Schachtzabel C, et al. Fronto-cingulate effective connectivity in obsessive compulsive disorder: a study with fMRI and dynamic causal modeling. Hum Brain Mapp 2010;31:1834-1850.

12. Nielen MM, Veltman DJ, de Jong R, Mulder G, den Boer JA. Decision making performance in obsessive compulsive disorder. J Affect Disord 2002;69:257-260.

13. Lawrence NS, Wooderson S, Mataix-Cols D, David R, Speckens A, Phillips ML. Decision making and set shifting impairments are associated with distinct symptom dimensions in obsessive-compulsive disorder. Neuropsychology 2006;20:409-419.

14. Cavallaro R, Cavedini P, Mistretta P, et al. Basal-corticofrontal circuits in schizophrenia and obsessive-compulsive disorder: a controlled, double dissociation study. Biol Psychiatry 2003;54:437-443.

15. Chamberlain SR, Fineberg NA, Menzies LA, et al. Impaired cognitive flexibility and motor inhibition in unaffected first-degree relatives of patients with obsessive-compulsive disorder. Am J Psychiatry 2007;164:335-338.

16. Fenger MM, Gade A, Adams KH, Hansen ES, Bolwig TG, Knudsen GM. Cognitive deficits in obsessive-compulsive disorder on tests of frontal lobe functions. Nord J Psychiatry 2005;59:39-44.

17. Olley A, Malhi G, Sachdev P. Memory and executive functioning in obsessive compulsive disorder: a selective review. J Affect Disord 2007;104:15-23.

18. Bechara A, Van Der Linden M. Decision-making and impulse control after frontal lobe injuries. Curr Opin Neurol 2005;18:734-739.

19. da Rocha FF, Malloy-Diniz L, de Sousa KC, Prais HA, Correa H, Teixeira AL. Borderline personality features possibly related to cingulate and orbitofrontal cortices dysfunction due to schizencephaly. Clin Neurol Neurosurg 2008;110:396-399.

20. Malloy-Diniz LF, Leite WB, de Moraes PH, Correa H, Bechara A, Fuentes D. Brazilian Portuguese version of the lowa Gambling Task: transcultural adaptation and discriminant validity. Rev Bras Psiquiatr 2008;30:144-148.

21. Cavedini P, Riboldi G, D'Annucci A, Belotti P, Cisima M, Bellodi L. Decisionmaking heterogeneity in obsessive-compulsive disorder: ventromedial prefrontal cortex function predicts different treatment outcomes. Neuropsychologia 2002;40:205-211.

22. Sheehan DV, Lecrubier $Y$, Sheehan $\mathrm{KH}$, et al. The Mini-International Neuropsychiatric Interview (M.I.N.I.): the development and validation of a structured diagnostic psychiatric interview for DSM-IV and ICD-10. J Clin Psychiatry 1998;59:22-33.

23. Goodman WK, Price LH, Rasmussen SA, et al. The Yale-Brown ObsessiveCompulsive Scale (Y-BOCS). Part I: Reliability. Arch Gen Psychiatry 1989; 46:1006-1011.

24. Goodman WK, Price LH, Rasmussen SA, et al. The Yale-Brown ObsessiveCompulsive Scale (Y-BOCS). Part II: Validity. Arch Gen Psychiatry 1989;46: 1012-1016.

25. Beck AT, Ward CH, Mendelson M, Mock J, Erbaugh J. An inventory for measuring depression. Arch Gen Psychiatry 1961;4:561-571.

26. Beck AT, Epstein N, Brown G, Steer RA. An inventory for measuring clinical anxiety: psychometric properties. J Consult Clin Psychol 1988;56:893-897.

27. Rosario-Campos MC, Miguel EC, Quatrano S, et al. The Dimensional YaleBrown Obsessive-Compulsive Scale (DY-BOCS): an instrument for assessing obsessive-compulsive symptom dimensions. Mol Psychiatry 2006;11: 495-504.

28. Raven JC. The comparative assessment of intellectual ability. Br J Psychol 1948;39:12-19.

29. Malloy-Diniz L, Fuentes D, Leite WB, Correa H, Bechara A. Impulsive behavior in adults with attention deficit/hyperactivity disorder: characterization of attentional, motor and cognitive impulsiveness. J Int Neuropsychol Soc 2007;13:693-698

30. Cavedini P, Bassi T, Zorzi C, Bellodi L. The advantages of choosing antiobsessive therapy according to decision-making functioning. J Clin Psychopharmacol 2004;24:628-631.

31. Viswanath B, Reddy YCJ, Kumar KJ, Kandavel T, Chandrashekar CR. Cognitive endophenotypes in OCD: a study of unaffected siblings of probands with familial OCD. Prog Neuropsychopharmacol Biol Psychiatry 2009;33:610-615.

32. Parra FC, Amado RC, Lambertucci JR, Rocha J, Antunes CM, Pena SD. Color and genomic ancestry in Brazilians. Proc Natl Acad Sci USA 2003;100: 177-182. 